\title{
Maternal and Child Nutrition: Importance of the First 1000 Days
}

\section{Seray Kabaran}

Department of Nutrition and Dietetics, Faculty of Health Sciences, Eastern Mediterranean University, North Cyprus via Mersin 10, Turkey

The first 1000 days range from conception to the end of the child's second year of life [1]. The first 1000 days of life are characterized by rapid growth and development, maturation of all organ systems, and establishment of metabolic patterns. Also, in this period the fastest rate of neurodevelopment of cognitive functions occurs [2]. It is important to focus on healthy nutrition and development during the first 1000 days which will have benefits throughout life [1]. Nutrition quality and quantity during the first 1000 days affect the risk of developing chronic and metabolic diseases [2]. Children should maintain an adequate nutrition through proper maternal diet, exclusive breastfeeding for the first 6 months, starting adequate complementary foods after 6 months, and continued breastfeeding for up to age 2 [1].

The first 1000 days is a critical period of developmental plasticity: the capacity to express specific adaptive responses to environmental experiences. It has been shown that during this sensitive period organisms are affected by nutritional, hormonal, and metabolic environmental experiences, and that these experiences lead to lifelong consequences for health and wellbeing [3]. Early-life nutritional experiences can permanently program the cells' and organs structures, functions, and metabolism. Inappropriate metabolic and endocrine responses occur in organs like the brain, adipose tissue, muscle, liver, and pancreas. Structural and functional changes in the cells and organs due to changes in metabolic, neuroendocrine and immunologic responses, gene expression, and epigenetic mechanisms can cause fetal metabolic programming [2,4]. These factors affect growth, development and cognition, and the risk of cardiovascular diseases, metabolic disorders, allergies, and obesity [2].

Both low and high birth weights may lead to physiological and/or metabolic adaptations in vital organs, and may result in disruptions in normal growth and development [5]. Low birth weight is known to have important effects on a child's growth, development, and health status later in life. Stunting, greater susceptibility to infections, lower cognitive performance, and increased risk of adiposity, cardiovascular disease, diabetes mellitus, hypertension, and all-cause mortality happen more in low birth weight children in the long term. Higher birth weight has been shown to be associated with higher obesity, diabetes, and cancer risk in adult life. Therefore, prevention of both low and high birth weights through nutrition and health intervention is important during pregnancy [6].

It is known that maternal metabolism of obese women is altered in pregnancy, and off spring of obese mothers has a higher percentage of body fat. Maternal lifestyle, diet, body weight, and metabolism affect the utero metabolic environment which influences fetal body composition, metabolism and gene expression [7]. It is important to ensure a healthy and balanced diet during pregnancy to maintain the child's health throughout life. Also, both overweight and obese women that are planning to become pregnant have to lose their excess weight before pregnancy [8].

Another important issue in the first 1000 days that is related to nutrition is breastfeeding. Exclusive breastfeeding is recommended for the first 6 month of life, and then continued breastfeeding along with appropriate complementary foods for up to age 2 [8]. Human milk contains bioactive molecules like cells, immune factors, hormones,

\section{Publication History:}

Received: May 25, 2018

Accepted: July 04, 2018

Published: July 06, 2018

\section{Keywords:}

Child Nutrition, Breastfeeding, Overweight, Maternal metabolism

anti-infectious and anti-inflammatory agents, growth factors, and prebiotics that protect the infant against infection and inflammation, and contribute to immune maturation, organ development, and healthy microbial colonization [9]. Furthermore, breast-fed infants accept new vegetables more easily, and have higher acceptance of new foods when they are introduced during complementary feeding [10].

Complementary feeding practices are important to prevent obesity later in life. Six months of age is the optimal time to begin adequate complementary feeding [8]. Early repeated exposure to a wide variety of healthy foods and repeated exposure to the same food for up to eight times may facilitate the acceptance of new foods; especially vegetables. Infants that maintain daily variety in their diet accept new flavors more easily than infants that follow a monotonous diet. This underlines the importance of introducing a variety of foods in early childhood. Repeated early exposure to different foods could affect children's food preferences later in life [11-13].

There is a growing body of evidence which suggests that experiences during the first 1000 days of life can have long-term consequences for the child's health. Over nutrition in infancy and childhood, like consumption of diets that are high in energy, protein, sugar, sodium, and saturated fats also has long-term consequences, leading to inappropriate metabolic responses, changes in body composition, and increases the risk of becoming overweight, becoming obese and having chronic diseases in later life [2]. Adequate development and nutrition during the first 1000 days contribute to decrease in mortality and morbidity in children, increase in cognitive and motor development, increase in social performance and learning capacity, increase in adult height, and decrease in obesity and metabolic diseases [1]. As a conclusion, it is well recognized that the adequate nutrition for the mother and the child during this time can have a profound impact on the child's growth and development, and reduce disease risk.

\section{Competing Interests}

The author declare no competing interests.

"Corresponding Author: Dr. Seray Kabaran, Department of Nutrition and Dietetics, Faculty of Health Sciences, Eastern Mediterranean University, North Cyprus via Mersin 10,Turkey; E-mail: seray.kabaran@emu.edu.tr

Citation: Kabaran S (2018) Maternal and Child Nutrition: Importance of the First 1000 Days. Int J Clin Nutr Diet 4: 133. doi: https://doi.org/10.15344/2456$8171 / 2018 / 133$

Copyright: () 2018 Kabaran. This is an open-access article distributed under the terms of the Creative Commons Attribution License, which permits unrestricted use, distribution, and reproduction in any medium, provided the original author and source are credited. 
Citation: Kabaran S (2018) Maternal and Child Nutrition: Importance of the First 1000 Days. Int J Clin Nutr Diet 4: 133. doi: https://doi.org/10.15344/2456-

\section{References}

1. Cunha AJ, Leite ÁJ, Almeida IS (2015) The pediatrician's role in the first thousand days of the child: the pursuit of healthy nutrition and development. J Pediatr (Rio J) 91: 44-51.

2. Saavedra JM, Dattilo AM (2016) Nutrition in the First 1000 Days of Life: Society's Greatest Opportunity. In: Saavedra JM and Dattilo AM (Eds.) Nutrition in the First 1000 Days of Life: Society's Greatest Opportunity Early nutrition and long-term health: Mechanisms, consequences, and opportunities Woodhead Publishing, Elsevier, United Kingdom, pp. XXXVXliV.

3. Moore TG, Arefadib N, DeeryA, West S (2017) The First Thousand Days: An Evidence Paper. Parkville, Victoria; Centre for Community Child Health, Murdoch Children's Research Institute.

4. Kabaran S, Besler HT (2015) Do fatty acids affect fetal programming? J Health Popul Nutr 33: 14.

5. Fernandez-Twinn DS, Ozanne SE (2010) Early life nutrition and metabolic programming. Ann N Y AcadSci 1212: 78-96.

6. Ramachandran $P(2015)$ Maternal and child nutrition: The first 1,000 days. Indian J Med Res 142: 231-232.

7. Freeman DJ (2010) Effects of maternal obesity on fetal growth and body composition: implications for programming and future health. Semin Feta Neonatal Med 15: 113-118.

8. Pietrobelli A, Agosti M, MeNu Group (2017) Nutrition in the First 1000 Days Ten Practices to Minimize Obesity Emerging from Published Science. Int J Environ Res Public Health 14: 1491.

9. Ballard O, Morrow AL (2013) Human Milk Composition: Nutrients and Bioactive Factors. Pediatr Clin North Am 60: 49-74.

10. Scott JA, Chih TY, Oddy WH (2012) Food Variety at 2 Years of Age is Related to Duration of Breastfeeding. Nutrients 4: 1464-1474.

11. Kabaran S (2017) How can Early Life Flavor Experiences Affect Food Preferences? J Curr Pediatr 15: 38-46.

12. Barends C, de Vries J, Mojet J, de Graaf C (2013) Effects of repeated exposure to either vegetables or fruits on infant's vegetable and fruit acceptance at the beginning of weaning. Food Qual Pref 29: 157-165.

13. Maier A, Chabanet C, Schaal B, Issanchou S, Leathwood P, et al. (2007) Effects of repeated exposure on acceptance of initially disliked vegetables in 7-month old infants. Food Qual Pref 18: 1023-1032. 